\title{
Contemporary insights from Social Sciences Theory: Implications for Management
}

\author{
C. Callaghan* \\ School of Economic and Business Sciences, University of the Witwatersrand, Private Bag 3, Wits, 2050, South Africa \\ *To whom all correspondence should be addressed \\ chris.callaghan@wits.ac.za
}

\begin{abstract}
Management theory has a long history of drawing from social science theory to provide useful theoretical frameworks for managers. In resource constricted times, and in global contexts of uncertainty, the need for theory to provide insights for managers has perhaps never been so important. The objective of this research is to provide an analysis of seminal theory of paradigms and their incommensurability, and to offer a model which includes contemporary literature relevant to the challenges faced by management as a field. While certain pillars of social science theory have provided the bedrock upon which management has built certain of its literature, this paper argues not all social science tenets have been immune to the vagaries of contextual change over past decades. This paper seeks to revisit seminal social science literature on paradigms, and to derive a model of paradigm relationships in relation to management's relationships to other social sciences. Central to this reflexive engagement is the argument that social science validity is contingent on a multiplicity of perspectives, and that paradigm incommensurability is antithetical to notions of contemporary validity. Implications for management are drawn from the analysis.
\end{abstract}

\section{Introduction}

Management theory has a long history of drawing from social science theory to provide useful theoretical frameworks for managers. The need for novel theory development is perhaps particularly acute under conditions of technological change and increasingly prevalent innovative disruption of business models, markets and effectiveness of management processes and practices. The intellectual traditions of management are continually evolving to incorporate developments in other fields. According to Burrell and Morgan (1979:5), two major intellectual traditions have dominated social science debates over the preceding two centuries, namely (i) sociological positivism seeking to apply models and methods from the natural sciences to the study of social science, and (ii) German idealism, standing in opposition to this and based rather upon the premise that "ultimate reality of the universe lies in 'spirit' or 'idea' rather than in the data of sense perception," representing the subjective extreme to sociological positivism. According to Burrell and Morgan (1979:17), most sociological theory development can be classified according to two tensions. The first of these tensions relates to whether theory development is framed from a subjective versus an objective perspective. Theory development, according to the second of these tensions, tends to either explain the status quo, using "explanations of society in terms which emphasise its underlying unity and cohesiveness," or alternatively seeks to find explanations for the "radical change, deep seated structural conflict, modes of domination and structural contradiction" characterising modern society, and which "is essentially concerned with man's emancipation from the structures which limit and stunt his potential for development" (p.17). Burrell and Morgan
(1979:18) term the former the "sociology of regulation," which is represented in work by Durkheim, for example, and the latter a "sociology of radical change" which they explain further as follows:

The sociology of regulation tends to presume that various social characteristics can be explained in relation to these needs. It presumes that it is possible to identify and satisfy human needs within the context of existing social systems, and that society reflects these needs. The concept of 'deprivation', on the other hand [associated with the sociology of radical change], is rooted in the notion that the social 'system' prevents human fulfilment; indeed that 'deprivation' is created as the result of the status quo. The social 'system' is not seen as satisfying needs but as eroding the possibilities of human fulfilment. It is rooted in the notion that society has resulted in deprivation rather than in gain.

Premised on conflict between contrasting epistemological and ontological assumptions, this framework of Burrell and Morgan's (1979) incommensurate paradigms has important implications for management theory, or for the study of management. This paper seeks to make these implications explicit through a reconceptualization of these paradigmatic relationships. The objective of this paper is therefore to undertake a synthesis of certain literatures in order to derive implications for managers, and for managerial theory development. A modification of the Burrell and Morgan (1979) theoretical framework is offered, in order to incorporate into the model certain paradigmatic changes in ontological and epistemological assumptions, and to suggest novel assumptions that were not present in its original 
formulation, on account of recent technological changes in the social and business contexts within which managers need to operate. On the basis of this analysis, the argument is also made that radical changes in power relationships are occurring over time, particularly within a managerial context of increasing uncertainty where capital as an anchor to business no longer lends stability to firms as it used to. The Burrell and Morgan (1979) theoretical framework is modified to incorporate two additional paradigms, both associated with more radical forms of change that have been enabled by technological developments. The model derived in this paper therefore seeks to offer a useful framework for further management theory development, particularly in a globalised context of 'inverted' power relationships where managers no longer hold the same capitalistic power, or power backed by capital as was the case historically. Having briefly outlined the background to the paper, the knowledge problem it addresses is now considered.

\section{Knowledge problem}

The knowledge problem addressed in this paper is lack of knowledge relating to how contextual change over the past decades has reshaped certain relationships relating to Burrell and Morgan's theory of paradigm incommensurability, and how these notions link with research and practice in the management field, or the relatively unique contextual imperatives faced by management. To address this knowledge problem, a theoretical linkage is applied, as paradigm theory is first linked with critical theory perspectives, and then to an emerging body of literature suggesting further more radical paradigmatic change, with the source of this new radical change in social movements underpinned by technological change. At the heart of this synthesis is a consideration of the rise of the knowledge worker, and the related weakening of legitimacy of the manager in the wake of inversion of relationships between knowledge and capital. A re-constituted paradigmatic model is presented, with potentially useful implications for managers in contexts of increasing uncertainty and resource constraint, in that patterns of theory are described, which are arguably more stable than the contextual imperatives they describe and predict. It is argued this work is important, for the following reasons.

First, the Marxian paradigm of radical structuralism described by Burrell and Morgan (1979) arguably relates to an industrial paradigm, and perhaps therefore to the proliferation of theory and ideology premised on power relationships of high management power which does not sufficiently take into account the rising power of the knowledge worker power, which is based on their scarce tacit knowledge (Polanyi, 1973; Stone \& Deadrick, 2014). It is argued in this paper knowledge of consequences of contemporary power inversion associated with developments in knowledge management and changing human capital configurations (Mincer, 1958; Polanyi, 1973; Nonaka, 1994) is particularly important for management theory, given the rise of knowledge-based power, and the weakening of capitalbased power in organisational contexts. A revisit of Burrell and Morgan's (1979) framework, given these changes, and specifically given fundamental changes related to management over time (Deadrick \& Stone, 2014; Kaufman, 2014; Stone, Deadrick, Lukaszweski \& Johnson, 2014) is therefore taken to be important, given the need for contemporary reflexive theory development in social sciences in general and in management as a field in particular.

Second, critical theory has highlighted epistemological weaknesses in longstanding natural and social sciences approaches to assumptions, which stifle praxis, notably Habermas's (1970) notions of reconstruction of organisational conditions to emancipate human potential (Steffy \& Grimes, 1986), and Burrell and Morgan's (1979) theoretical framework has been challenged for its paradigm incommensurability thesis (see Willmott, 1993). Given critical theory's usefulness as a conceptual frame which grounds social science applications to working contexts in a normative humanist rationale (Alvesson \& Willmott, 1992), conceptions of paradigms can also be considered through the critical theory 'lens;' arguably, given centrality of power and its interrelationships in management theory, a reframing of key social theory applied to management in light of contemporary change facing the field is important, and reflexivity offered by critical theory interrogation is considered particularly important.

Third, changes in power relationships in workplace contexts have perhaps disrupted assumptions of stability of paradigm lenses such as those of Burrell and Morgan (1979), but these disruptions in turn arguably have their causal channels and mechanisms, which are to some extent related to emergent technological developments (Stone, Deadrick, Lukaszweski \& Johnson, 2014) which have radically enhanced knowledge worker productivity through improved knowledge management (Nonaka, 1994), notwithstanding inconsistent uptake of knowledge and "stubborn traditionalism" on the part of organisations (Boudreau \& Lawler, 2014:232). Vulnerability of theory to new evidence and ideas (Lakatos, 1970; Callaghan, 2016a) cannot be shielded through seminal status, however, and it is argued here that management theory needs to consistently review and interrogate itself to remain relevant and useful in what seem to be increasingly uncertain contexts, in which managerial power is no longer wedded to logics of capital.

Given the argued importance of the contribution of this work, this paper therefore seeks to revisit seminal social science literature on paradigms, deriving a model of paradigm relationships re-fitted to contemporary management context imperatives, seeking a match between contemporary contextual management imperatives and paradigmatic differentiations more suited to management's unique location in relation to other social sciences. The paper is structured as follows.

Literature relating to Burrell and Morgan's (1979) paradigmatic differentiation of social science assumptions is first considered, and certain tenets of critical theory are introduced to structure discussion, which lead up to arguments posed later. Ontological and epistemological 
assumptions of social science research are considered in relation to the Burrell and Morgan model, and a synthesis of theory and literature is undertaken to provide a model incorporating further ontological and epistemological perspectives, which it is argued are absent from literature. Finally discussions centre on arguments that paradigm incommensurability is antithetical to emerging theory relating to first order socio-technical change, which is in turn arguably driving second order change in power relationships within societies and organisations. The theoretical model derived from this analysis is discussed, and the paper concludes with a consideration of derived implications for management. Having argued for the importance of the contribution of this paper, Burrell and Morgan's (1979) conceptions of social science paradigmatic differentiation are now considered.

\section{Paradigmatic theory}

According to Burrell and Morgan (1979:1), all "social scientists approach their subject via explicit or implicit assumptions about the nature of the social world and the way in which it may be investigated" namely (i) ontological assumptions relating to the "very essence of the phenomena under investigation" such as whether 'reality' is external to an individual or produce of individual consciousness; (ii) epistemological assumptions, or those relating to the grounds of knowledge, its forms (tangibility) and how 'truth' of knowledge can be established, and its objective versus subjective nature; and (iii) assumptions concerning human nature and the environment, and issues of determinism versus voluntarism, or the extent to which destiny is determined by external forces or internal will.

However, for Burrell and Morgan (1979), a dominant tension in the social sciences exists between these assumptions according to whether they relate to an objective or subjective view of the world (ontology), to the nature of knowledge (epistemology), as well as human nature and social sciences methodology. Burrell and Morgan (1979:3) explain the subjective perspective as follows:

If one subscribes to the alternative view of social reality, which stresses the importance of the subjective experience of individuals in the creation of the social world, then the search for understanding focuses upon different issues and approaches them in different ways. The principal concern is with an understanding of the way in which the individual creates, modifies and interprets the world in which he or she finds himself. The emphasis in extreme cases tends to be placed upon the understanding and of what is unique and particular to the individual rather than what is general and universal. This approach questions whether there exists an external reality worthy of study. In methodological terms it is an approach which emphasises the relativistic nature of the social world to such an extent that it may be perceived as 'anti-scientific' by reference to the ground rules commonly applied in the natural sciences.
At this nexus it might be important to consider carefully these notions, and the questioning of objectivity, or the implicit questioning of rationality implied in this framework, if questioning of objectivity can be taken to be akin to a critique on rationality. However, before considering issues related to rationality, which are tackled in later sections, it is important to relate Burrell and Morgan's (1979) conceptions to the normative lens of critical theory. This is considered important, as critical theory perspectives are central to discussions which follow.

According to Steffy and Grimes (1986:325) critical theory is "most succinctly defined as an empirical philosophy of social institutions" retaining both empirical-analytic and interpretive components, but with each within a "reflective system of epistemic inquiry," with certain implications. These implications include the need for critical discussion of subjective and theoretical aspects of observers and observed (as in hermeneutics) but also consideration of (i) limitations of alternative modes of enquiry, (ii) analysis of relationship between community of organisational researchers and practitioners and members, and (iii) acknowledgement of practical aims of particular modes of research (Steffy \& Grimes, 1986). As such these concerns relate to the issues raised by Burrell and Morgan's (1979) schema and critique of social science assumptions in general.

As method, critical theory is also not without its explicit aims, these being (i) critique of ideology, or the "cult of scientism" in social theory and its methods, whereby technical reasoning dominates, and political or other forms of reasoning are displaced, or other paradigms deemed 'inferior,' which results in reduction of praxis, or the "intentional organising actions of subjective actors" (to counter scientism analysis of ontological, epistemological and methodological assumptions underlying research is made explicit); (ii) developing "an organization science capable of changing organisational processes" and minimising "objectification" of organisational actors, and avoiding denial of motivating interests in research (Steffy \& Grimes, 1986:326). Arguably, any perspective that seeks to unconditionally shut down another potentially poses a threat to validity of the intellectual project; Campbell and Fiske's (1959) notion of discriminant validity can perhaps be usefully brought to bear on these discussions, where validity is increased through multiple perspectives of phenomena.

Burrell and Morgan (1979:3) relate their paradigmatic schema (Figure 1) to methodological implications, offering a perspective of a continuum along which extremes are differentiated with regard to each of four fundamental assumptions according to subjectivist versus objectivist approaches; according to this scheme, (i) ontological assumptions can differ according to nominalism (subjectivist) versus realism (objectivist) dimensions, (ii) epistemological assumptions according to anti-positivism (subjectivist) versus positivism (objectivist) extremes, (iii) human nature according to voluntarism (subjectivist) versus determinism (objectivist) dimensions, and (iv) methodology, according to ideographic (subjectivist) versus nomothetic (objectivist) dimensions. Burrell and Morgan (1979:23) juxtapose 
sociologies of radical change with regulation and subjective and objective approaches to social science to develop a matrix, offering four paradigms which offer "contrasting standpoints and generate quite different concepts and analytical tools." These are each considered as follows.

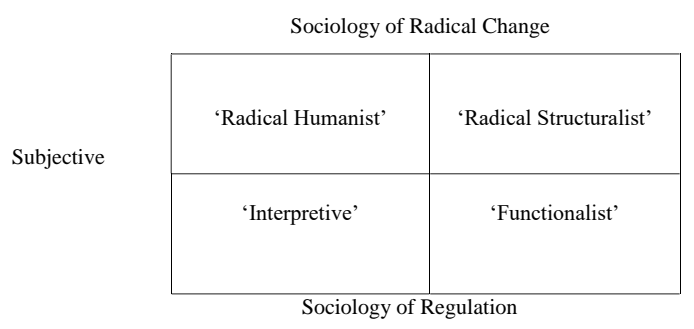

Objective

Figure 1: Burrell and Morgan's (1979:22) four paradigms for analysis of social theory

\section{Ontological assumptions: Nominalism versus Realism}

Relating to ontology, nominalism (or conventionalism), contrasts with realism, with the view the world "external to the individual revolves around the assumption that the social world external to individual cognition is made up of nothing more than names, concepts and labels which are used to structure reality" and which are "regarded as artificial creations whose utility is based upon their convenience as tools for describing, making sense of and negotiating the external world" (Burrell \& Morgan, 1979:4). In contrast, realism postulates "the social world external to individual cognition is a real world made up of hard, tangible and relatively immutable structures" independent of naming or human perceptions (p.4).

It is argued here that recent technological developments have spawned a new era (Alexander, 2014) of mass communication on the back of social media and Internet connectivity which has resulted in a sea of change in the way reality can be socially constructed (Berger \& Luckmann, 1966), as movements such as citizen science (Swan, 2012; Torr-Brown, 2013; Bonney, Cooper, Dickinson, Kelling, Phillips, Rosenberg \& Shirk, 2009), participant-led research (Vayena \& Tasioulas, 2013) and post-normal science (Funtowicz \& Ravetz, 1994) herald increased engagement of populations with the front line of objectivity, represented by the engagement with the natural sciences, or participation in the scientific research process. Arguably, these movements represent a convergence of collective intelligence (Malone, Laubacher \& Dellarocas, 2007; Woolley, Chabris, Pentland, Hashimi \& Malone, 2010) as population perceptions of the 'crowd' engage directly with the bedrock of realism in the form of objective science itself through increased transparency and engagement.

These changes, arguably, reflect a convergence between the subjective, or socially constructed reality of 'things' and what seems to constitute an objective reality. It is possible these changes in social forces enabled by social media and Internet technologies have yet to fully work their way through societies, but it is argued here these are powerful forces, and a reconceptualization of Burrell and Morgan's (1979) model is necessary, in order to incorporate these changes and provide a theoretical platform for further management theory development in contemporary contexts.

Given the mechanisms and causal channels predicted by these bodies of theory, two additional category groups, or new paradigms, are incorporated into Burrell and Morgan's (1979) model. This process of incorporation is shown in Figure 2. These two additional paradigms are termed the 'Radical Emergence' and 'Radical Verificationist' paradigms, the former representing the rising presence of the crowd in social media and Internet connectivity, which can under certain conditions manifest as subjective engagement (Surowiecki, 2004) and under others act as a mechanism of objective research and quality control, and as a safeguard against incorrect science (Funtowicz \& Ravetz, 1994), or verification of truth in objective science, which is taken here to be related to the Radical Verificationist paradigm. These two new paradigms differ according to the subjective and objective axis, notwithstanding a tendency toward ultimate convergence. Arguably, the potential for radical breakthroughs in natural and social science exists as these forces for radical change work through multiplier effects and chains of causality, and human connectivity increases the potential for knowledge creation effectiveness, ultimately offering transcendence of knowledge aggregation problems, or the difficulties inherent in bringing together and combining knowledge, particularly tacit knowledge, across geographical and other boundaries (Hayek, 1945; von Hippel, 1994).

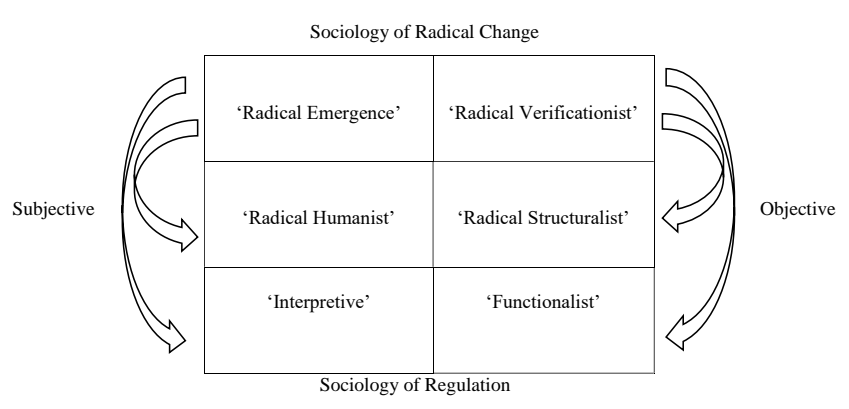

Figure 2: Modified Burrell and Morgan paradigmatic assumptions representation

\section{Epistemological assumptions}

Relating to epistemology, anti-positivism contrasts with positivism, and poses a critique to positivism's claims that "hypothesised regularities can be verified by an adequate experimental research programme" (verificationists) or that hypotheses can only be falsified (falsificationists), as well as the positivist tenet knowledge creation is fundamentally cumulative; anti-positivism typically takes different forms, but all are united by a stance "firmly set against the utility of a search for laws or underlying regularities in the world of social affairs" (Burrell \& Morgan, 1979:4). This is another dimension of the subjective-objective axis. 
Epistemologically, however, the radical emergence paradigm incorporates theory (Swan, 2012; Torr-Brown, 2013; Bonney et al., 2009) which explicitly links populations, or the crowd, to knowledge creation, and this body of theory can also be taken to represent a methodology, premised on an epistemology based on transparency and maximised collaboration with populations themselves. The operationalisation of an epistemology which incorporates the subjectivity of the crowd aligns with perspectives of knowledge that go beyond positivistic rationales, and the radical emergence paradigm is taken to incorporate the subjectivist perspective. Chaotic systems (Levy, 1994) can emerge from large scale involvements of crowd data collection and analysis, or involvement in science enabled by social media and Internet technologies (Callaghan, 2015; 2016b), which can add complexity to subjective dimensions of crowd engagement, and this complexity is taken to be a feature of the radical emergence paradigm. The claim that science cannot generate objective knowledge of any kind is, however, not a feature of the radical emergence paradigm, as emergent complexity of maximised engagement and transparency in knowledge creation arguably makes such 'strong' claims problematic. The arrows in Figure 1 represent the reflexivity provided by heuristics of engagement with these two new paradigms, as new streams of literature (from which these paradigms are derived) enable more realistic perspectives of the other paradigms, either through enhanced subjective or objective knowledge.

The social world, for anti-positivists, is relativistic and can only be understood from the point of view of individuals directly involved, and social science is taken to be a subjective and not an objective enterprise, whereby antipositivists "tend to reject the notion that science can generate objective knowledge of any kind" (Burrell \& Morgan, 1979:4). Given the radical extremes of incorporation of populations in its epistemology, as reflected in participant-led research (Vayena \& Tasioulas, 2013), and in an emerging stream of literature namely probabilistic innovation (Callaghan, 2015) which draws epistemological lessons from real time knowledge creation, the nature of radical emergence (as well as verificationist theory and the ultimate potential for convergence) seems to belie the notion objective knowledge cannot result. In fact, what this body of epistemological literature and theory seems to suggest is that one simply cannot know what knowledge will emerge and in what form it will emerge in. On the frontier of radical change epistemology, new forces remain unidentified, and presupposing absolute states of knowledge is perhaps an arrogance which conflicts with Campbell and Fiske's (1959) notion of a need for complementarity of perspectives. Given the radical change potential of radical emergent and verifactionist paradigms, complementarity of perspectives is perhaps necessary in order to epistemologically validate emergent phenomena associated with radically accelerated knowledge creation. This can enable a convergence of perspectives, and a more valid understanding of phenomena.

In terms of assumptions between voluntarism and determinism, the determinist view takes the environment or situation to completely determine human life and its activities, which contrasts with the voluntarist perspective that autonomy and fee will dominate external influences (Burrell \& Morgan, 1979:5). Whereas for centuries the voluntarist and determinist (Burrell \& Morgan, 1979) dichotomy has been espoused in terms of agency and structure, the extreme radical change paradigms of emergence and validation share a focus on open platforms of participation in science, and it is argued here that theory development in both paradigms offer not only convergence in complementarity of perspectives, but also a platform for knowledge creation to test the limits of voluntarism versus determinism. As open access to citizens to engage with science (and also its validation) expands exponentially, a new era of knowledge creation can be enabled, and agency of the crowd is expanded exponentially, pushing up against the frontiers of determinism, and making explicit the ultimate potential of human agency in the face of phenomena.

With regard to methodology, the ideographic approach contrasts with the nomothetic approach in that it regards the social world as understandable only through first-hand knowledge of phenomena, emphasising involvement in the "everyday flow of life- the detailed analysis of the insights generated by such encounters with one's subject and the insights generated by such encounters" with one's subject and insights from different sources; in contrast, the nomothetic approach stresses use of systematic protocol and applying hypothesis testing using quantitative techniques under conditions of scientific rigour (Burrell \& Morgan, 1979:5). Both approaches can be used inductively or deductively. Arguably, the emergence of new technologies, and new methods facilitating population engagement in science also underpins a new methodology with hitherto unrealised potential for large-scale data collection and analysis, such as those using social media in disaster management (Alexander, 2014) or crowdsourcing applied to real time problem solving and crowdsourced R\&D (Callaghan, 2015). Again, in contrast to Burrell and Morgan's (1979) paradigm incommensurability theory, the modified schema offered by this paper (Figure 2) draws from Campbell and Fiske's (1959) conception of complementarity, and argues validity is best increased by incorporating different paradigmatic perspectives of phenomena. However, barriers between paradigms are maintained as useful conceptual heuristics in the model presented in Figure 2. It is to the issue of incommensurability that discussions now turn.

\section{Paradigm incommensurability}

Burrell and Morgan's (1979:23) four paradigms are "defined by very basic meta-theoretical assumptions which underwrite the frame of reference, mode of theorising and modus operandi of the social scientists who operate within them," each identifying a separate social-scientific reality. Burrell and Morgan (1979:25) stress that these paradigms:

[O]ffer different ways of seeing. A synthesis is not possible, since in their pure forms they are contradictory, being based on at least one set of opposing metatheoretical assumptions. They are alternatives, in the 
sense that one cannot operate in more than one paradigm at any given point in time, since in accepting the assumptions of one, we defy the assumptions of all the others.

Burrell and Morgan's (1979) notion of incommensurability of paradigms is, however, not uncontested. According to Willmott (1993:681) this notion "declared a new dogma" which is essentially at odds with Kuhn's recognition of continuity existing together with incommensurability in theory development. For Willmott (1993), although Burrell and Morgan's (1979:682) work heralded progress in the "emancipation of organisational analysis from the confines of functionalist assumptions" its "support for theory development is, at best, ambivalent" because " its division of social and organisational analysis into four, mutually exclusive enclaves or 'paradigms' lacks credibility, and is therefore poorly equipped to counter functionalist hegemony." Willmott (1993:682) stresses that "if taken seriously, the central argument of Paradigms [Burrell and Morgan's (1979) work] unnecessarily constrains the process of theory development within polarized sets of assumptions about science and society." Any perspective maintaining polarisation and opposing synthesis is potentially violating tenets of validity, as firewalls to knowledge constrain multiplicity of perspectives, and constrain assessment of convergent and discriminant validity, in terms of Campbell and Fiske's (1959) seminal conceptions of validity.

According to Willmott (1993:682/683), in his seminal paper on paradigm incommensurability:

Paradigms assumes, and strongly endorses, a restriction of analysis within the confines of four, mutually exclusive 'ways of seeing.' It is with the dualistic mentality of Paradigms that this paper takes issue. Specifically, the paper is critical of its polarization of 'subjective' versus 'objective' approaches to social science. By representing methodological diversity as a dualism- as an either/or- a tendency for social and organizational theory to gravitate to one or other of these poles is effectively cast into a metaphysical principle, thereby promoting a new form of closure because the coherence of all attempts to resist this tendency is denied... Not only does the mutual exclusivity these place (unnecessary) constraints upon theory development, but it is very doubtful whether, as a strategic device, it can cut much ice with those who are disinclined to accept its assumptions, or are determined to defy its demands.

The modified Burrell and Morgan typology represented in Figure 2 represents a similar differentiation of paradigms, but explicitly takes these to not be incommensurate, but as useful conceptual and theoretical heuristics. As heuristics, this model is taken to better reflect the spirit of attempts to usefully apply principles from different paradigms to deepen theory development (see Lewis \& Grimes, 1999).

Willmott (1993) stresses the importance of understanding Kuhn's consideration of the dynamics of scientific knowledge development, whereby anomaly accumulation can stimulate alternative theorising. According to Kuhn (1970), theory development in 'normal science' typically occurs within a paradigm, but anomaly accumulation can lead to revolutionary change of paradigms. This contrasts with Lakatos's (1970) notion of scientific fields which retain core assumptions and act to protect this core from emergent evidence challenging it. Implicit in these concerns are the dangers inherent in any closure, or silencing of voices in academic discourse, or abetting the emergence of a new form of hegemonic closure (Willmott, 1993) which is a feature of Burrell and Morgan's (1979) rigid conceptions of paradigm incommensurability.

For Willmott (1993:687), these rigid conceptions [of Burrell and Morgan, 1979] also run counter to Kuhn's (1970) central thesis that "paradoxical processes of struggle" are at the heart of new paradigm emergence, as "development of 'new' theory is necessarily mediated by the detection of inconsistencies and anomalies in its predecessor." Willmott (1993:683) acknowledges natural versus social sciences differences (as well as Kuhn's (1970) argument of lack of consistent direction of ontological development in natural sciences, or convergence of theory with representations of nature despite clear indications of paradigm replacement), as in social science evidence of progressive supercedence of paradigms is scant, some arguing it is 'pre-paradigmatic' or has yet to achieve maturity and dominance of a single paradigm.

Latour (2000:114) stresses the "imitation of the natural sciences by the social sciences has so far been a comedy of errors," as two polarised approaches to study emerged, namely to adopt an objective approach akin to the natural sciences, or a hermeneutic, interpretative approach. Arguably, addressing the complexity of human engagement with knowledge creation requires a reflexive approach, malleable to emergent knowledge, and not the closing off of streams of theory development from each other. Arguably the extension of Burrell and Morgan's (1979) model (Figure 2) incorporates a temporal aspect, reflecting change in conceptions of theory development over time, and offers the prediction of convergence also between natural and social sciences.

According to Latour (2000:114), the "old tired theme of social construction has been turned on its head since scholars are now busy trying to show the ingredients with which some lasting order is being maintained" as what "was the cause is now the provisional consequence" as society is "not made of social functions and factors." What seems to be reflected in these critiques of Burrell and Morgan's schema is an inherent contestation within social science theory development over time, a contestation which cannot, however, be solved through the ring-fencing of theoretical neighbourhoods, which seems to have been Burrell and Morgan's (1979) point of departure. There seems to be no easy way to arrive at social 'truth' and it is perhaps best to allow contestation to ultimately produce an emergent consensus over time. The extreme radical change paradigms shown in Figure 2, namely the radical emergence and radical verificationist perspectives are taken to represent ontological and epistemological 
processes which each take recourse to populations themselves, or the crowd, in order to create new knowledge, whether manifested in subjective emergent crowd forces or in objective emergent crowd forces specifically focused on scientific knowledge creation in the verificationist (Popper, 1972) tradition.

Probabilistic innovation theory, to the extent it essentially describes these two paradigms, predicts a convergence of the subjective and the objective in the social and natural sciences, although without predicting the 'truth' of which side final consensus will fall. Instead, the emergent properties of a consensus based on maximum inclusivity and transparency are predicted to take on probabilistic characteristics, and as inclusiveness is exponentially increased, so knowledge creation outputs are expected to also increase exponentially. Probabilistic innovation theory is effectively premised on the same ontological and epistemological assumptions reflected in the radical emergence and radical verificationist paradigms, essentially reflecting a stream of literature with its origins in a body of work relating to how inclusiveness, or engagement of large numbers of participants can solve problems (create believed knowledge) by managing the knowledge aggregation problem. Further explanation of the probabilistic innovation literature stream is offered as follows.

Examples of the probabilistic innovation literature stream include work relating knowledge aggregation to the problem of estimating almost exactly the weight of an ox in a market (Galton, 1907), the nature of the knowledge aggregation problem itself (Hayek, 1945; Polanyi, 1973), the way the crowd solves problems of determining market prices (Fama, 1970: Smith, 2003[1776])), the accuracy of predictive betting markets (Hanson, 2003), the harnessing of collective intelligence (Woolley et al., 2010), the emergent properties of distributed, self-organising systems (Johnson, 1998; Kochogovindan \& Vriend, 1998), and how to harness (both objective and subjective) wisdoms of crowds (Surowiecki, 2004) versus 'mobs' (Le Bon, 1895), as well as how emergent computation principles of self-organisation (Forrest, 1990) which are mirrored in collective insect 'swarm intelligence' (Bonabeau \& Théraulaz, 2000) can be applied to real time knowledge creation and problem solving. These are just certain examples of this stream of literature, as a deeper exploration of other theoretical literature bodies within the radical emergence and radical verificationist academic 'space' is beyond the scope of this work.

Willmott (1993:688) also questions assumptions implying natural science's types of progress are inevitable or indeed desirable for social science, and the notion social science should progress via the same path; as perhaps "the so-called pre-mature condition of the social sciences at once reflects and preserves a significant degree of resistance to the scientization of irremediably practical, moral problems and issues" and "politics of social science " rendered transparent, and can be "judged to be more or less compatible with, or supportive of, diverse political philosophies." In line with post normal science tenets (Funtowicz \& Ravetz, 1994) which derive from problems posed by inconstant and contradictory climate change research and which take recourse to maximised transparency and involvement of populations of those affected to verify or provide scrutiny to science, research within the radical verificationist paradigm is taken to challenge all preconceived assumptions of science, allowing for a more inclusive paradigm of scientific research, whether social or natural.

Another probabilistic innovation assumption should be noted here, however; that scientization reflected in the weaponisation of science and industrialisation of methods of war associated with the World Wars, and related ideologies, are fundamentally antithetical to mechanisms of transparency and maximised inclusiveness in decision making suggested by post normal science (Funtowicz \& Ravetz, 1994). In other words, it is perhaps the closing-off of voices and the discourse space which allows for atrocities and events which violate legitimate collective interests. Arguably, Burrell and Morgan's (1979) aversion to paradigm synthesis, as argued by Willmott (1993), is not helpful, as it can perhaps lead to closure from the scrutiny and action of populations, thus perhaps enabling scientization itself.

The radical emergence and radical verificationist paradigms both represent the radical change enabled through exponentially increased connectivity, as light is increasingly being shed on all aspects of science, and academic thought exposed to increasing scrutiny of entire populations of citizens, increasingly involved in scientific research itself (Swan, 2012; Torr-Brown, 2013; Bonney et al., 2009; Vayena \& Tasioulas, 2013), as stakeholders, or all affected by science, both social and natural, add their voices. Arguably, emergent technologies such as crowdsourcing, crowdfunding, crowdsourced R\&D (Callaghan, 2015) and social media (Alexander, 2014) have enabled the emergence of these two paradigms, but the real emancipatory potential of these effects are perhaps yet to be fully realised. In Figure 3 , certain forces underlying paradigmatic change are identified, and the emergence of the radical emergence and radical verificationist paradigms are shown to be a function of these forces. As technological change creates social change, the interactive effects of this change emerge as sociotechnical change, which influences the contexts in which managers operate. What this implies is that managers need to incorporate into their management the effects of technology, which have not only resulted in new opportunities and threats, but have also disrupted power dynamics in markets and within organisations.

An example of this process is the way that ideas and innovations can more easily find funding, and capital is no longer enough to guarantee a return to firms. Knowledge and ideas enabled by technology imply that it is the human capital in organisations that is increasingly important to these returns. The practical implication of this is that human resources and talent management may become increasingly important over time in relation to physical capital. Theory that predicts that individuals are necessarily exploited by capital is no longer as effective at predicting relationships when the power has shifted away from capital ownership structures towards those with ideas and knowledge. 


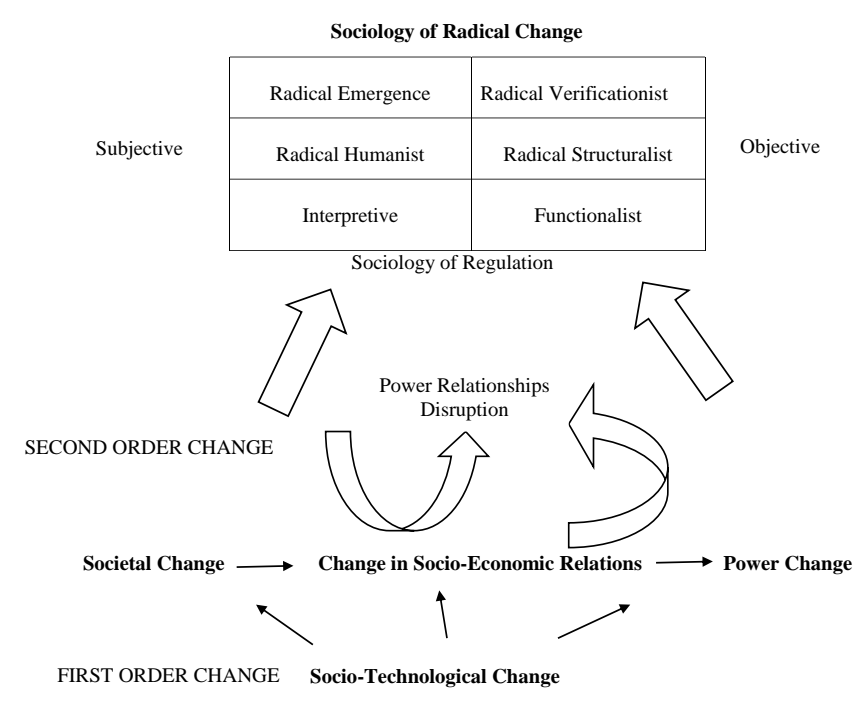

Figure 3: Adapted Paradigm Model located in relation to first- and second-order forces for structural change

These effects, however, are expected to have implications for the different assumptions underlying the radical emergence and radical verificationist paradigms. The radical emergence paradigm relates to subjective ontological and epistemological assumptions which relate to how, for example, new technologies influence how subjectivity can impact conditions in a technologically enabled world and in the way knowledge is created and perceived in such a context. In simple terms, these changes can be seen in the way voters are influenced by social media, leading to outcomes such as the exit of the United Kingdom from the European Union (Brexit), and other political events. Arguably, such voting does not maximise the objective utility of voters, in a context in which globalisation, or openness (a key issue in the Brexit referendum) has long been known to drive economic growth and other positive outcomes (Dreher, 2006). Similarly, in an era where perceptions are a function of 'fake news' or social media and television content that can be akin to propaganda, managers need to be aware of how subjectivity can influence the business context. Another example of the implications of this paradigm is the need for increased investments in knowledgeable and innovative human resources and their retention, as intrinsic factors (which are inherently subjective) are increasingly key to employee decisions to stay with a firm for longer.

The radical verificationist paradigm, on the other hand, relates to ontological and epistemological assumptions related to how scientific knowledge creation and how the use of knowledge will change in a world that is increasingly interconnected by technology. Managers will increasingly be able to use different forms of knowledge, and an important example of this is the use of customers to drive innovation, or to use social media for this purpose. Other examples abound, of how technology is changing worldview conceptions or ontologies, and how it is changing epistemologies, or methodologies, validity-issues, and knowledge creation itself. These changes therefore have implications for managers who continue to draw insights from certain long- held assumptions in the social science literature. Other social science literature has explored ideas related to the 'emancipation' of human potential. These ideas are now considered in relation to the development of the radical emergence and radical verificationist paradigms, and implications for management are highlighted.

\section{Radical emergence and verificationist paradigms: Praxis}

Steffy and Grimes (1986:330) suggest definitions of praxis derived from Habermas (1973) are appropriate, related to how individuals rationally analyse and reconstruct organisational conditions and themselves, with an ethical commitment to ultimately emancipate human potential, and as per Habermas' (1973) definition, the social scientist's purpose is to "unify theory, practice, and praxis in order to liberate social members" which is a process at odds with instrumental activity determined primarily by technical reasoning, which can reduce to technical control and manipulation and withdrawal of the subjective self, further resulting in alienation. Arguably, much social science theory related to organisations has developed its bedrock conceptions in the wake of the industrial revolution, when capital had monopoly power over the individual. However, disruption introduced by new productive technologies (Callaghan, 2016) may have given rise to disruption of managerial power in organisations, and the rise of the knowledge worker, requiring a new paradigm of management premised on developing commitment and satisfaction. Arguably, this power inversion is a signal of further radical change in society and organisations to come, as the first order change associated with new technologies is transmitted to change in power relationships. This process is shown in Figure 3. The radical emergence and verificationist paradigms are taken here to incorporate reflexivity as a fundamental characteristic of both, as openness and transparency in science (Funtowicz \& Ravetz, 1994) heralds a new era of causal mechanisms or channels which transmit first order socio-technological change to second order disruption of power relationships in societal contexts, and therefore in contexts of research and theory development. This change is considered to have humanist and emancipatory effects, 'closing the circle of science' as populations affected by science (both social and natural) are given voice, and stakeholders are enabled through new technologies of connectivity to be actively involved in emergent discovery and verification of knowledge creation itself. Arguably, this process is an operationalisation of praxis, in the humanist spirit of Habermas (1973).

\section{Implications for management}

Management theory development has drawn heavily from the social sciences, and Burrell and Morgan's (1979) paradigmatic differentiation is a seminal framework used for theory development. However, as stressed by Willmott (1993), the notion of paradigm incommensurability is problematic, and Alvesson and Willmott (1992) have argued management theory should strive for praxis and apply 
emancipatory normative frameworks, but at the same time should not tear down functional aspects of power structures which are not problematic. It is argued here that negotiating this tension between different paradigmatic perspectives is necessary, and that is it is important not to avoid the complexities of synthesis, given the theoretical and practical problems of management require problem solving, which draws from multiple perspectives and trans-disciplinary theory and practice. Arguably, the following are therefore important implications for managers.

Firstly, wrongheaded theory development and practice has a cost for management. This includes assumptions based on unsound premises. Causes of business failure are multiple, as scientific literature on failure is spread "over multiple disciplines" (Pretorius, 2008:408), and South African businesses and organisations face complex and longstanding challenges, including skills shortages, infrastructure backlogs, and other challenges which constrain country growth (Stanz, 2009) in a context of low levels of entrepreneurship (Pretorius, Nieman \& van Vuuren, 2005). Management theory therefore needs to offer theoretical frameworks useful in light of these challenges. Forcing theoretical frameworks to be orthogonal denies needs of management who require theory that can provide problem solving insights, and the modification of Burrell and Morgan's (1979) typology to incorporate synthesis and to also incorporate emergent theory related to technological advances and literatures may improve the value of the paradigm model for managers.

Secondly, the radical emergent and radical verificationist paradigms derived from literature in this paper arguably offer important insights for management, in that they frame new developments in citizen science, participant-led research, and the increasing power, engagement and inclusion of populations and crowds in matters that affect them. This includes business and organisational management, as stakeholders assert their claims, all the while global interconnectivity is being ratchetted up. With increasingly vocal stakeholders and societies, management faces both the more subjective (and unpredictable) forces of emergence of the crowd, with an environmental and social activism increasingly empowered through social media, as well as the more objective forces of crowd emergence embodied in new potential of crowdsourced $R \& D$ and crowdsourcing for organisational data collection, analysis and problem solving (and its competitive advantage benefits, as well as those applied to marketing and engagement with populations of clients and customers).

Thirdly, the identification of trends in the literature offered in this paper is arguably useful for managers who face uncertainty of technological development (framed as first order change), and need to better understand its influences on power (relationships of second-order change) in organisations. Managers may face diminishing power in contexts where tacit knowledge (Polanyi, 1973; Nonaka, 1994) is increasingly leveraged by emergent technologies, and the relative power of capital to knowledge is diminishing. Caught between these effects and increasing global uncertainty, it is argued theory development and management practice that takes advantage of management planning and roadmaps developed using principles related to the two extreme radical change paradigms considered here (Figure 2) can benefit from the heuristic properties of the model. These heuristics properties challenge longstanding assumptions and instead incorporate not only technological change but also power relationships into paradigms of management theory development.

\section{Conclusions}

The objective of this research was to provide an analysis of Burrell and Morgan's (1979) theory of paradigms and their incommensurability, and to offer a model which includes contemporary literature relevant to the challenges faced by management as a field. Such analysis was considered particularly important in light of substantive shifts in theory development and literature related to the emergence of new technologies (Alexander, 2014) of mass communication enabled by social media and Internet connectivity (Swan, 2012; Torr-Brown, 2013; Bonney et al., 2009; Vayena \& Tasioulas, 2013) and new modes of science enabled by these new technologies (Funtowicz \& Ravetz, 1994), termed here first order change, and the increased power of the crowd, or stakeholder populations, as well as knowledge workers in organisational contexts, or second order change. Two further paradigms were incorporated into the Burrell and Morgan model on the basis of this literature, and implications for management were derived. Arguably, management theory and practice draws from inherently multidisciplinary perspectives, and its problems require synthesis of perspectives rather than closure, and therefore paradigm incommensurability is problematic. Arguably, in the South African context of resource constraint and uncertainty, taking recourse to opportunities associated with the growing literature on emergent technologies and increased engagement with stakeholder crowds and markets can be particularly useful.

\section{References}

Alexander, D.E. 2014. 'Social media in disaster risk reduction and crisis management', Science and Engineering Ethics, 20(3): 717733.

Alvesson, M. \& Willmott, H. 1992. 'On the idea of emancipation in management and organization studies', Journal of Management Studies, 39(5): 619-644.

Berger, P.L. \& Luckmann, T. 1966. The social construction of reality. Harmondsworth: Penguin.

Burrell, G. \& Morgan, G. 1979. Sociological paradigms and organisational analysis. London: Heinemann.

Bonabeau, E. \& Théraulaz, G. 2000. 'Swarm smarts', Scientific American, 282(3): 72-79.

Bonney, R., Cooper, C.B., Dickinson, J., Kelling, S., Phillips, T., Rosenberg, K.V. \& Shirk, J. 2009. 'Citizen science: A developing tool for expanding science knowledge and scientific literacy', BioScience, 59(11): 977-984. 
Boudreau, J. \& Lawler, E.E., 2014. 'Stubborn traditionalism in HRM: Causes and consequences', Human Resource Management Review, 24: 232-244.

Callaghan, C.W. 2015. 'Crowdsourced 'R\&D' and medical research', British Medical Bulletin, 115:1-10.

Callaghan, C.W. 2016a. 'Capital-centric versus knowledge-centric paradigms of human resource management: A historical perspective', Acta Commercii, 16(1): 1-11.

Callaghan, C.W. 2016b. 'A new paradigm of knowledge management: Crowdsourcing as emergent research and development', Southern African Business Review, 20(1): 1-28.

Campbell, D. T. \& Fiske, D.W. 1959. 'Convergent and discriminant validation by the multitrait-multimethod matrix', Psychological Bulletin, 56: 81-105.

Deadrick, D.L. \& Stone, D.L. 2014. 'Human resource management: Past, present, and future', Human Resource Management Review, 24: 193-195.

Dreher, A. 2006. 'Does globalisation affect growth? Evidence from a new index of globali-sation', Applied Economics, 38(10): 10911110.

Fama, E. 1970. 'Efficient capital markets: A review of theory and empirical work', The Journal of Finance, 25(2):383-417.

Forrest, S. 1990. 'Emergent computation: Self-organizing, collective, and cooperative phenomena in natural and artificial computing networks', Physica D, 42: 1-11.

Funtowicz, S.O. \& Ravetz, J.R. 1994. 'Uncertainty, complexity and post-normal science', Environmental Toxicity and Chemistry, 13(12): 1881-1885.

Galton, F. 1907. 'Vox populi (the wisdom of crowds)', Nature, 1949(75): 450-451.

Habermas, J. 1970. Toward a rational society. (Translated by Shapiro, J.J.). Boston: Beacon Press.

Habermas, J. 1973. Theory and practice. (Translated by Viertel, J.). Boston: Beacon Press.

Hanson, R. 2003. 'Combinatorial information market design', Information Systems Frontiers, 5(1): 107-119.

Hayek, F.A. 1945. 'The use of knowledge in society', American Economic Review, 35(4): 519-530

Johnson, N.L. 1998. Collective problem solving. Los Alamos National Laboratory Working Paper LA-UR-98-2227. Http://collectivescience.com/Documents_1/Johnson\%20Collective \%20Problem\%20Solving\%20AB\%20paper\%20v11f\%201998.pdf

Kaufman, B.E. 2014. 'The historical development of American HRM broadly viewed', Human Resource Management Review, 24: 196-218.

Kochugovindan, S. \& Vriend, N.J. 1998. 'Is the study of complex adaptive systems going to solve the mystery of Adam Smith's “invisible hand"?', Independent Review, 3(1): 53-66.
Kuhn, T. S. 1970. The structure of scientific revolutions. $2^{\text {nd }}$ Edition. Chicago: University of Chicago Press.

Lakatos, I. 1970. Falsification and the methodology of scientific research programmes. In I. Lakatos and A. Musgrave (Eds.) Criticism and the growth of knowledge. Cambridge: Cambridge University Press.

Latour, B. 2000. 'When things strike back: A possible contribution of 'science studies' to the social sciences', British Journal of Sociology, 51(1):107-123.

Le Bon, G. 1896. The Crowd: A Study of the Popular Mind. [Online] available: http://www.gutenberg.org/cache/epub/445/pg445.html

Levy, D. 1994. 'Chaos theory and strategy: Theory, application, and managerial implications', Strategic Management Journal, 15: 167178.

Lewis, M.W. \& Grimes, A.J. 1999. 'Metatriangulation: Building theory from multiple paradigms', Academy of Management Review, 24(4): 672-690.

Malone, T.W., Laubacher, R. \& Dellarocas, C. 2010. 'The collective intelligence genome', Sloan Management Review, 5(3): 21-31

Mincer, J. 1958. 'Investment in human capital and personal income distribution', The Journal of Political Economy, 66(4): 281-302.

Nonaka, I. 1994. 'A dynamic theory of organizational knowledge creation', Organization Science, 5(1): 14-37.

Polanyi, M. 1973. Personal knowledge: Toward a post-critical philosophy. London: Routledge \& Kegan Paul.

Popper, K.R. 1972. Objective knowledge. An evolutionary approach. London: Oxford University Press.

Pretorius, M., Nieman, G. \& Van Vuuren, J. 2005. 'Critical evaluation of two models for entrepreneurial education: An improved model through integration', International Journal of Educational Management, 19(5): 413-427.

Pretorius, M. 2008. 'Critical variables of business failure: A review and classification framework', South African Journal of Economic and Management Sciences, 11(4): 408-430.

Smith, A. 2003. The wealth of nations (1776). New York: Bantam Dell.

Stanz, K. 2009. Factors affecting employee retention: What do engineers think? Management Today, 17-19. [Online] available: http://repository.up.ac.za/dspace/bitstream/handle/2263/12199/Stan z_Factors $\% 282009 \% 29$.pdf? sequence $=1 \&$ is Allowed $=y$

Steffy, B.D. \& Grimes, A.J. 1986. 'A critical theory of organization science’, Academy of Management Review, 11: 322-336.

Stone, D., Deadrick, D.L., Lukaszweski, K.M. \& Johnson, R. 2014. 'The influence of technology on the future of human resource management', Human Resource Management Review, 25: 216-231.

Surowiecki, J. 2004. The wisdom of crowds. London: Little, Brown.

Stone, D.L. \& Deadrick, D.L. 2014. 'Challenges and opportunities affecting the future of human resource management', Human Resource Management Review, 25: 139-145. 
Swan, M. 2012. 'Crowdsourced health research studies: an important emerging complements to clinical trials in the public health research ecosystem', Journal of Medical Internet Research, 14(2): e46

Torr-Brown, S. 2013. 'Crowdsourcing for science and medicine: progress and challenges', The Journal of OncoPathology, 1(2):7581

Vayena, E. \& Tasioulas, J. 2013. 'The ethics of participant-led biomedical research', Nature Biotechnology, 31(9):786-787.

Von Hippel, E., 1994. "'Sticky information" and the locus of problem solving: Implications for innovation', Management Science, 40(4): 429-439.

Willmott, H. 1993. 'Breaking the paradigm mentality', Organization Studies, 14(5): 681-719.

Woolley A.W., Chabris, CF., Pentland, A., Hashmi, N. \& Malone TW. 2010. 'Evidence for a collective intelligence factor in the performance of human groups', Science, 330(6004): 686-688. 